\title{
De Delia a Marcela: preludios cervantinos en el prólogo de la Tercera parte de Espejo de príncipes y caballeros*
}

\author{
Almudena IZQuierdo AndReU**
}

\begin{abstract}
Resumen
Este artículo analiza los paralelismos entre la pastora Delia y su enamorado Polio Sincelo, y Marcela con Grisóstomo. La primera se localiza en el prólogo de la Tercera parte del Espejo de príncipes y caballeros (1587), y la segunda en la Primera parte del Quijote (1605). Este trabajo examina los elementos comunes de ambas historias, como los rechazos de Delia y Marcela, y las muertes posteriores de Polio Sincelo y Grisóstomo. Asimismo, se estudian los epitafios que se colocan sobre sus tumbas. Por otro lado, se profundiza en el tratamiento que dan a Delia y Marcela los personajes masculinos de las historias, quienes las tachan de mujeres crueles e ingratas.
\end{abstract}

Palabras clave: pastores; libro de caballerías; Marcela; Quijote; Tercera parte de Espejo de príncipes y caballeros; prólogo.

Title: From Delia to Marcela: Cervantes' Preludes in the Prologue of the Tercera parte de Espejo de príncipes y caballeros

\begin{abstract}
This article analyses the parallels between the shepherd Delia and her lover Polio Sincelo, and Marcela with Grisóstomo. The first one is localised at Tercera parte del Espejo de principes y caballeros's prologue (1587), and the second one at the Part I of the Quixote (1605). This paper examines the common elements between both stories, like the rejections of Delia and Marcela, and the subsequent deaths of Polio Sincelo and Grisóstomo. In ad-

* Este artículo se integra dentro del proyecto I+D «BETA: Bibliografía Española de Textos Antiguos (II)» (ref. FFI2015-69371-P), y «La construcción narrativa en los ciclos de caballerías hispánicos» (ref. PAPIIT IN 405919). También se vincula con los objetivos del grupo de investigación «Sociedad y literatura hispánicas entre la Edad Media y el Renacimiento» (ref. 941032) de la Universidad Complutense de Madrid. Agradezco a Álvaro López su lectura de este trabajo.

** École Normale Supérieure de Lyon. aiandreu@ucm.es / ORCID iD: https://orcid.org/00000001-7408-3046
\end{abstract}


dition, it studies the epitaphs which are placed on their graves. On the other hand, it delves into the treatment given to Delia and Marcela by the male characters of the stories, who name them merciless and ungrateful women.

Keywords: Shepherds; Chivalry Book; Marcela; Quixote; Tercera parte de Espejo de príncipes y caballeros; Prologue.

\title{
Cómo citar este artículo / Citation
}

Izquierdo Andreu, Almudena. 2021. «De Delia a Marcela: preludios cervantinos en el prólogo de la Tercera parte de Espejo de príncipes y caballeros». Anales Cervantinos 53: 113-132. https://doi.org/10.3989/anacervantinos.2021.004

\author{
A Ángel Gómez Moreno, \\ maestro y mentor
}

\section{INTRODUCCIÓN}

El influjo de la literatura pastoril o de las historias de pastores en los libros de caballerías es uno de los ingredientes que enriquecen la ficción caballeresca durante el desarrollo y la maduración del género. Oficialmente, fue Feliciano de Silva quien comenzó la introducción del personaje del pastor y de elementos pastoriles en sus libros de caballerías de los años treinta, hasta el punto de convertir esta veta temática en una marca propia de su estilo (Cravens 1976). Sin embargo, se cuenta con posibles antecedentes ya desde el Amadís de Gaula (1508) con el retiro del héroe a la Peña Pobre tras el rechazo de Oriana (Riley 1982).

Con el tiempo, el elemento pastoril pasó a ser un condimento más que aderezaba la narrativa caballeresca, especialmente con el desarrollo del género como libro de evasión en la segunda mitad del siglo XVI (Lucía Megías y Sales Dasí 2008, 77-79). Esta situación va en consonancia con el surgimiento del género como tal de los libros de pastores a partir de los años cincuenta del Quinientos con Los siete libros de la Diana de Jorge de Montemayor como obra inaugural en 1559 , un texto que se reeditó al menos veinte veces en el siglo XVI. La Diana determinó la producción pastoril posterior, así como la configuración de un género que, en líneas generales, cuenta con una estructura cerrada y marcada, hasta bien entrado el siglo XVII con Los pastores del Betis (1633) de Gonzalo de Saavedra ${ }^{1}$.

1. Para una panorámica del libro de caballerías se puede consultar Prieto (1986) y, más específicamente, Eisenberg y Marín Pina (2000), Cacho Blecua (2007), Lucía Megías y Sales Dasí (2008), 
Tras los primeros ensayos del género en las décadas precedentes con la traducción al castellano de la Arcadia de Sannazaro (1547) o las Églogas de Garcilaso de la Vega, la Diana supone la explosión de un conocido ambiente pastoril, etiquetado ya como género propio que se convertirá en una de las corrientes de prosa más importantes del Renacimiento español, especialmente en la segunda mitad del siglo XVI. A la Diana le siguen numerosas continuaciones y epígonos, lo que ayudó a configurar una estética delicada y elegante en el que colaboraron Cervantes con su Galatea (1585) y Lope de Vega con su Pastores de Belén (1612), este último ya en el siglo XVII.

Llegados a este punto, hay que señalar que en el siglo XVI la convivencia entre diferentes tendencias novelísticas o literarias, ya sean en prosa o en verso, conllevó la influencia mutua entre corrientes narrativas, como es el caso del libro de caballerías, que adoptó el personaje del pastor en numerosas narraciones. El carácter 'híbrido' del género caballeresco sirve para ampliar el corpus de caracteres o de personajes tipo. Lo que empezó siendo una intervención episódica o de tipo anecdótico, se convirtió en un elemento recurrente en las aventuras caballerescas que potencia la trama y el escenario original.

Una vez que el tipo del pastor se asienta en el libro de caballerías, se exhibirá en los textos su manejo de lírica, su sensibilidad poética y compositiva o sus conocimientos de leyendas clásicas. En muchas ocasiones las escenas que protagonizan los pastores se enclavan en un ambiente bucólico que les permite expresar su virtuosismo musical mediante el uso de la flauta, el rabel o la churumbela, junto con su talento poético, lo que posibilita que el libro de caballerías se enriquezca notablemente con estas notas pastoriles (Lucía Megías y Sales Dasí 2008, 214-215; del Río 2001 y 2002).

El ensayo de Silva entre los años treinta y cincuenta del siglo XVI fue todo un éxito, por lo que el tema pastoril se convierte en un ingrediente que complementa la historia caballeresca. De forma paralela al surgimiento de los libros de pastores con Los siete libros de la Diana de Montemayor, la ficción caballeresca sigue su propia senda con el tipo del pastor ya plenamente integrado. En palabras de Martín Romero, «la recurrencia de lo pastoril en los libros de la segunda mitad del siglo XVI se debe a un proceso de acentuación de rasgos ya existentes en el género desde las aportaciones de Feliciano de Silva» $(2009,566)$. Su presencia no faltará en los libros que ronden la mitad del siglo XVI en adelante, cobrando un especial interés en la segunda parte del Quinientos, sobre todo con el desarrollo del libro de caballerías como género de evasión, corriente a la que se adscribe esta Tercera parte de Espejo de príncipes y caballeros (1587) de Marcos Martínez, que se comentará a continuación. Durante época filipina, la «moda del bucolismo» (Ferrer 1999, 14) se pudo apreciar notablemente en los salones cortesanos, así como en el ámbito literario mediante las narraciones caballerescas y pastoriles que fueron

Marín Pina (2011) y Mérida Jiménez (2013). Para la literatura pastoril son fundamentales los libros de Avalle-Arce (1975) y López Estrada (1974). 
de la mano, y gozaron de gran éxito. A pesar del descenso en la publicación de libros de caballerías, debido sobre todo a numerosas crisis de la imprenta sobrevenidas especialmente en los últimos cincuenta años del siglo XVI (Alvar y Lucía Megías 2001), el éxito de la prosa caballeresca se mantuvo, y los textos introdujeron diversos elementos pastoriles que enriquecieron considerablemente los relatos (Martín Romero 2009).

Previamente a la obra de Martínez, el pastor es una figura constante en las ficciones caballerescas de la segunda mitad del siglo XVI, como se pone de manifiesto en el Olivante de Laura (1564) de Antonio de Torquemada, Febo el Troyano (1576) de Esteban Corbera, la Segunda parte de Espejo de príncipes y caballeros (1580) de Pedro de la Sierra y Rosián de Castilla (1586) de Joaquín Romero de Cepeda (Martín Romero 2009, 566). En estas obras, el elemento pastoril se consagra por ejemplo con la presencia del pastor Silvano en el Olivante, homónimo del personaje de la obra de Montemayor, y que conocería bien Torquemada (Muguruza 1995, 200). Por su parte, Febo el Troyano introduce una escena en la que dos pastores, Silvaneo y Lusitano, defienden ideas contrarias del amor y la mujer. Por señalar solo un ejemplo más, en la Segunda parte de Espejo de príncipes y caballeros la trama sentimental de Clariano, el héroe caballeresco, resulta ser un episodio bucólico en sí mismo (Martín Romero 2009, 573-580)².

Por último, y como tema principal de este artículo, se lleva a cabo una comparativa entre dos personajes femeninos pastoriles, Delia, invención de Martínez en su Tercera parte de Espejo de príncipes y caballeros, y Marcela, la huidiza pastora que Cervantes creó en la Primera parte del Quijote (1605). En este punto, quiero matizar que el trabajo busca analizar las similitudes entre este episodio pastoril-caballeresco inserto en la Tercera parte de Espejo de príncipes y caballeros, un libro de caballerías tardío de 1587, y el episodio cervantino, sin que ello quiera decir que exista dependencia alguna. Su interés deriva de la sintonía de intereses por parte de dos autores, Cervantes y Marcos Martínez, ante el género pastoril y el caballeresco en fechas muy cercanas. No hay que olvidar que Cervantes publicó La Galatea en 1585, en Alcalá de Henares, donde dos años después Martínez dio a la imprenta su Tercera parte del Espejo de príncipes y caballeros, cuyo prólogo tanto podría haber interesado a Cervantes por sus experimentos metaficcionales, como se analiza a continuación.

\section{LA PASTORA ESQUIVA DE MARCos MartíNEZ: LA AVENTURA DE DELIA}

La Tercera parte de Espejo de príncipes y caballeros nace en 1587 en las prensas de Alcalá de Henares. El licenciado Marcos Martínez firma este título, que cierra las continuaciones impresas del ciclo de Espejo de príncipes y

2. El tema pastoril de esta obra se puede ampliar en Martín Romero (2007). 
caballeros. El texto cuenta con tres ediciones conocidas y localizadas: la princeps de 1587 en Alcalá de Henares por Juan Íñiguez de Lequerica; la segunda, datada en 1587 y 1588 en la misma ciudad por el mismo impresor; y más tarde, una tercera edición de la que solo existen menciones, impresa en 1589. Finalmente, en 1623 se publica la última en Zaragoza por parte de Pedro Cabarte. Fue precisamente en esta edición de Zaragoza donde los Libros III y IV del escrito se colocaron como el I y II de una presunta Cuarta parte, de ahí que las continuaciones manuscritas se etiqueten a sí mismas como Quinta parte de Espejo de príncipes y caballeros y Quinta y sexta parte de Espejo de príncipes y caballeros ya en el siglo XVII. Sobre el autor, Marcos Martínez, apenas hay datos, referidos todos ellos por sí mismo; el más llamativo de todos es que se presenta como vecino de la propia Alcalá. Parece probable que hubiera estudiado en la misma Universidad Complutense, donde podría haber obtenido el título de licenciado con el que firma, un indicio de su incipiente labor literaria, humanística y letrada (Eisenberg y Marín Pina 2000, 331-332; Martínez 2012, X; Campos García-Rojas 2006, 7-8).

Esta Tercera parte continúa las aventuras caballerescas de personajes como Claridiano, Claramante y don Heleno, todos ellos descendientes del emperador Trebacio, quien fue el iniciador de la genealogía en el primer libro de la saga (Campos García-Rojas 2012). Según se desarrollan las diferentes partes del ciclo, se aprecia cómo se transforma el paradigma amadisiano clásico al introducir novedades y diversos recursos estéticos para encandilar al público, de modo que se consagre definitivamente esa propuesta del libro de caballerías ya no solo como lectura de entretenimiento, sino también de evasión (Campos García-Rojas 2015, 17).

La estructura de esta Tercera parte se desarrolla en torno a un conflicto bélico de dimensiones mundiales que sirve para enaltecer la figura del emperador, así como su corte, frente a las civilizaciones infieles o paganas. La historia se localiza en su mayoría en Oriente, lo que aporta a la obra un exotismo destacado, además de abrir las miras de los caballeros a lugares lejanos y desconocidos, de manera que se produzcan contactos entre pueblos y culturas civilizadas, paganas o salvajes. La narración no evitará el paradigma tradicional de los libros de caballerías al echar mano de elementos heredados de la tradición literaria, que se convierten en marcas que permiten reconocer la historia como propia del género. A ellos se suma la presencia de mujeres guerreras, aventuras maravillosas, episodios marcados por el humor, travestismo de damas en pajes, o la influencia de la materia clásica por la aparición del mito del laberinto de Creta y la presencia del personaje de Medea en el prólogo (Martínez 2012, XI-XIII; Campos García-Rojas 2015, 10-11).

Es notable también el empleo de composiciones poéticas, pues el libro cuenta con una gran variedad de metros. El uso de letras, motes y otros versos se plasma en torneos e intrigas amorosas al ser dos situaciones propicias para exhibir este tipo de composiciones. Aparte, tenemos textos líricos que nacen al calor de las escenas pastoriles, donde el estilo de vida desocupado y alejado de la esfera social urbana da rienda suelta a la creatividad poética de 
los caballeros y damas. Se trata de un espacio certero para la expresión de sus sentimientos y desahogo de sus penas amorosas, de manera que se retoma la idea de cómo la vida natural puede ayudar a aliviar el alma y el espíritu. El disfraz de pastor otorga una libertad a las damas y a los caballeros para la composición de sonetos y canciones que celebren su amor o alivien sus penas (Martínez 2012, XIII-XVI; Campos García-Rojas 2006, 9-10; 2015, 13-46; Campos García-Rojas y Martin 2018, 65-78). De esta forma, las escenas pastoriles cobran una gran importancia en la trama al propiciar la composición de versos líricos, y por la versatilidad que otorga a la historia la mezcolanza pastoril y caballeresca.

Precisamente, estos episodios pastoriles resultan de vital importancia para el tema que se plantea en este trabajo, pues es justo el primero de ellos, localizado en el prólogo literario del libro de la primera edición, el que más me interesa en este momento. La escena pastoril que se narra, en la que se ve involucrado el personaje ficcionalizado del autor, Marcos Martínez, recoge un momento semejante a la famosa escena de la pastora Marcela y el suicidio de Grisóstomo ante el amor no correspondido de la joven, escrita por Cervantes para la Primera parte del Quijote. No se trata, ni mucho menos, de afirmar que el pasaje pastoril de Marcos Martínez en su prólogo a la Tercera parte de Espejo de príncipes y caballeros sea la fuente de la historia de Marcela y Grisóstomo, pero sí creo interesante apuntar ciertas conexiones y paralelismos que comparten ambas narraciones.

El prólogo literario de la Tercera parte de Espejo de príncipes y caballeros es uno de los paratextos más interesantes que hay dentro del conjunto del género caballeresco, hasta el punto de que ha merecido trabajos específicos sobre su desarrollo y su función dentro de la $\mathrm{obra}^{3}$. En relación con la dedicatoria anterior, el prólogo literario de la Tercera parte de Espejo de príncipes y caballeros funciona igual que los del Silves de la Selva, Olivante de Laura y Febo el Troyano, donde aparte de estar precedido también por una dedicatoria a un noble, narra el hallazgo maravilloso del manuscrito del libro por parte del autor. Hay que decir que, a lo largo de este original prólogo, Marcos Martínez retoma el tópico del manuscrito encontrado y de la falsa traducción, con la diferencia de que el autor ficcionalizado forma parte de la historia al introducirse dentro de la trama narrativa y ponerse a un nivel similar que el resto de los sabios cronistas que habían puesto por escrito las aventuras de los familiares del emperador Trebacio. El prólogo juega con diversos elementos que terminan por configurar una síntesis de la materia caballeresca, es

3. Los paratextos que figuran en su obra son bastante numerosos, y ocupan tanto los obligatorios desde el punto de vista legal, como los literarios, que aquí nos interesan. En primer lugar, se encuentran los preliminares de tipo legal, compuestos por el privilegio del libro, firmado en nombre del Rey por Pedro Zapata de Mármol, escribano de cámara; una fe de erratas y la tasa del precio de venta del libro. Más adelante se hallan los preliminares literarios formados por una carta dedicatoria al conde de Melgar; una serie de composiciones poéticas, en concreto nueve sonetos dirigidos también al mismo noble y, por último, el prólogo de la obra, en el que se encuentra el episodio pastoril en cuestión (Martínez 2012). Para un trabajo específico del prólogo literario del libro, véase Campos García-Rojas (2010). 
decir, el paratexto emplea recursos literarios que caracterizan e individualizan el género del libro de caballerías. Marcos Martínez crea una historia marcada por la aventura maravillosa del autor convertido en personaje ficcional, donde tienen un importante papel los episodios pastoriles, el viaje al Otro Mundo con el tema del descensus ad inferos, motivos y tópicos caballerescos como el autor-personaje, además de la falsa traducción y manuscrito encontrado ya mencionados, así como el motivo ecdótico, configurado por los diferentes autores de la historia (Campos García-Rojas 2010). Según Campos GarcíaRojas, el prólogo de Martínez es un texto literario que desdibuja sus fronteras con la obra ficticia; ya no se trata solo de referir y justificar la escritura del libro, sino que la relación de causas y la presentación de antecedentes se crean desde la misma ficción, no desde un plano externo al universo ficticio en el que se narra la obra. Marcos Martínez se embulle en la narración como un personaje más de la historia donde recibe el manuscrito original de la Tercera parte de Espejo de príncipes y caballeros, la orden de traducirlo y darlo a conocer (ibid., 507).

Para Campos García-Rojas, el prólogo resulta moderno y novedoso, a pesar de que beba de las fuentes medievales, perceptible por el influjo directo de los prólogos desde la Antigüedad junto con los motivos que lo configuran. Si bien cuenta con una serie de funciones y motivos caracterizadores, el paratexto de Marcos Martínez supone una ruptura con los modelos caballerescos previos, tanto por su forma como por su función. A través de su relato onírico, este prólogo comienza con un nuevo juego argumental no muy habitual. Se fortalecen además las cualidades literarias del prólogo, así como las conexiones que establece con el resto del cuerpo del relato hasta que, por su forma y contenido, termina por equipararse a una aventura caballeresca más, como si de un capítulo agregado a la narración principal se tratase: es por ello una gran novedad a pesar de seguir las estelas de Olivante de Laura y Febo el Troyano. El autor re-crea un prólogo que supone un gran ejercicio narrativo que no habría sido posible con el paradigma ya no solo recreativo, sino de evasión con el que juega ahora el libro de caballerías, y que en este punto alcanza técnicas que son prácticamente «pre-cervantinas» (ibid., 518).

El prólogo se narra en primera persona por el autor convertido ahora en personaje de la historia, es decir, como un carácter autorreferencial igual al que juega Beatriz Bernal en el prólogo del Cristalián de España. Marcos Martínez cuenta cómo salió a pasear por el campo a las afueras de Alcalá de Henares, en concreto por la ribera del Henares; allí le sorprende la noche, lo que le lleva a buscar refugio. Estos datos nos pueden confirmar el lugar de residencia del autor y dónde pudo escribir la obra, un hecho sustentado también por la información extraída de la impresión de la obra, cuya primera edición nace igualmente en la ciudad complutense. Tras una primera disculpa de Martínez, enmarcada dentro de la tópica de la captatio benevolentiae, se describe el tiempo de la aventura, que resulta ser un momento para nada casual. Los hechos maravillosos se producen el día de san Juan; además, el 
autor ubica el lugar exacto donde comienza la aventura: cerca de Alcalá de Henares y del río, de manera que la realidad cotidiana de una pequeña ciudad de Castilla se mezcla con el espacio maravilloso de corte medieval donde se produce una historia con tintes pastoriles y caballerescos. Las aguas cristalinas, las flores y las avecillas que describe Martínez configuran un locus amoenus, un espacio que no escapa del simbolismo que se aplicaba a estos parajes durante la Edad Media, y que continúa durante el Renacimiento; de esta manera, se prefigura la aventura y lo sobrenatural, junto con la historia amorosa que tendrá lugar en ese momento (ibid, 510-511).

A continuación, se produce un primer cruce entre la realidad y la fábula de la ficción que narra Martínez por medio del sueño, o más concretamente, del cansancio que siente el autor, que le empuja a querer dormir dentro de la choza que ha encontrado para refugiarse en la noche. Se trata, en palabras de Campos García-Rojas, de un momento onírico, en el que Marcos Martínez describe su estado emocional y físico para expresar su cansancio: «... donde no con poco contento di algún descanso a mis molidos miembros, dulcemente durmiendo, al son de las cristalinas aguas y ruido de los verdosos olmos» (Martínez 2012, 11). Con estas palabras, el lector infiere que Martínez ha caído dormido debido al cansancio del paseo, es más, se expresa en pasado, de forma que el autor certifica que es un hecho que ha ocurrido. No obstante, acto seguido, este momento confirmado queda desmentido por el propio Martínez, quien confiesa que nunca llegó a dormirse, negando así lo que previamente había aseverado: «Mas antes que mi cansado cuerpo tomar pudiesse aquel descanso, con unas lastimeras vozes, que a son de un sonoroso rabel los siguientes versos referían» (ibid., 11). Se podría intuir, como bien hace Campos García-Rojas, que Marcos Martínez despertó de su sueño, del que no había llegado a descansar debido al sonido del rabel del pastor Polio Sincelo que aparece a continuación ${ }^{4}$. En cualquier caso, la frontera entre la realidad y la fícción está marcada por el sueño, justamente ese estado onírico que separa el paseo de Marcos Martínez por una zona realista, la ribera del Henares, del campo idílico en el que se va a desarrollar el episodio pastoril y, más adelante, la aventura caballeresca, esta última espaciada por otro proceso de cambio de escenario de Martínez a través de la cueva.

La historia continúa con Marcos Martínez escuchando a un pastor llamado Polio Sincelo cantar su amor no correspondido por otra pastora, Delia: «Mas

4. El investigador señala la estructura onírica del relato como el esqueleto básico en el que se desarrolla el prólogo, de forma que los sucesos narrados son fundamentales en tanto al desarrollo del argumento. Marcos Martínez emplea su prólogo como un puente entre las dos primeras partes del ciclo y su propia obra, de modo que recopila los hechos ya producidos. El sueño permite dar continuidad a los episodios de los otros autores, además de incorporarse a las aventuras, da legitimidad a su narrador por medio de él como protagonista. Martínez sueña, cree soñar y vive la aventura. Asimismo, el autor no necesita ningún pretexto para introducir el elemento maravilloso en forma de aventura, pues este rasgo ya forma parte del género caballeresco. El prólogo resulta tener una estructura narrativa que lo convierte en un texto literario que narra una aventura, con aspecto de sueño en la que se volatilizan las fronteras entre la realidad y la ficción caballeresca (Campos García-Rojas 2010, 508-509). 
antes que mi cansado cuerpo tomar pudiesse aquel descanso, con unas lastimeras vozes, que a son de un sonoroso rabel los siguientes versos referían». Mediante un soneto, Polio declara su amor a Delia, pero le reprocha los sufrimientos y tormentos a los que lo ha sometido por su ignorancia y rechazo. Al salir Marcos Martínez de la choza, ve al «penoso pastor» que había cantado el soneto junto a la bella pastora Delia. Frente a las súplicas de Polio Sincelo, que reclama a Delia que tenga a bien sus sentimientos, la pastora presenta una realidad diferente. Descubrimos que está casada y, por medio de otro soneto, la joven declara que, para demostrar el verdadero amor que siente Polio o cualquiera por ella, es necesario entrar en la cueva del sabio Anglante:

Por esso, Polio, entiende que impossible te ha de ser de otra suerte amor pagado hasta que a sólo tú la milagrosa

ventura por tu ánimo sobrado mostrándote en valor muy invencible, entres por la gran cueva tenebrosa.

Polio Sincelo se horroriza ante la declaración de Delia, pues señala que su petición será su final, dado que no entró jamás un hombre vivo en la cueva que no pagara tal atrevimiento con la muerte. Tras estas palabras, el pastor hace ademán de atrapar a Delia. Ante este movimiento, la pastora pasa fugazmente delante del autor al tratar de huir de Polio Sincelo: «Pues viendo la pastora el falso intento de su desdichado amante, no ay gamo que a su aventajada ligereza igualasse...» (Martínez 2012, 13). Si bien este último trata de forzar a Delia para que acepte su amor, ella huye mientras el pastor intenta alcanzarla, en una escena que casi nos recuerda a la ninfa Dafne escapando del caprichoso Apolo, según la leyenda ovidiana. Ante esta situación, Marcos Martínez interviene para ayudar a Delia, deteniendo a Polio, a quien recuerda que la bella pastora está casada y no tiene derecho a tratarla de ese modo. Sin embargo, este le explica su versión de los hechos. La «ingrata» Delia, como la llama, obliga a sus enamorados a entrar en la cueva del sabio Anglante, un espacio que más adelante visitará Marcos Martínez como marco de su recorrido del descensus ad inferos:

O invidioso mancebo, ¿qué te movió a estorvar mi presurosa carrera, guiadora a satisfazer mi penosas quexas, que tan debilitada tienen mi triste vida, aviendo innumerable tiempo traído trastocado el juizio d'este sin ventura Polio, comunicando mis passiones y su fuerte coraçón el resonante eco? Dexarás mi dichosa y particular suerte acabar su començado viaje, pues aunque cumpliera mi firme desseo, no estuviera mi atormentado coraçón satisfecho de la antigua deuda. Anda, anda orgulloso mancebo a la encantada cueva del sabio Anglante, si quieres gozar de la ingrata pastora, porque éste es el galardón que d'ella reciben los que en sólo su servicio se emplean (Martínez 2012, 13). 
Tras el rechazo y la intervención del autor, Polio Sincelo, con un tono lastimero y lleno de patetismo, hace una declaración sobre su desdichada suerte, apela a Marcos Martínez a que sea él quien entre en la cueva del sabio Anglante y se despide realizando una serie de invocaciones a diferentes elementos naturales, como a las flores, las aguas cristalinas, el ganado, o incluso al Eco al que tantas veces contaba sus cuitas amorosas. Tras su discurso, termina suicidándose por la imposibilidad de conseguir el amor de Delia: «No huvo acabado de dezir estas razones el infeliz Polio Sincelo, cuando con unos lastimosos sospiros, diciendo: "Ay Delia mía causadora de mi triste suerte", dio el ánima al passagero Aqueronte, dexando que del lastimoso caso muy admirado» (Martínez 2012, 14). Ante la escena que acaba de contemplar, el personaje de Marcos Martínez da sepultura al pastor cavando su tumba con un pequeño cuchillo que llevaba consigo. Además, para que su historia no cayera en el olvido, graba en la corteza de un sauce un soneto en el que se recuerde la historia del joven antes de continuar su aventura a través de la cueva (Campos García-Rojas 2010, 507):

\author{
Bien puede rebolver su curso el cielo \\ [aviendo] las naciones trastocado \\ [haziendo] rebolver a lo humanado \\ con cuando está criado en el suelo. \\ Primero se verá caliente el yelo, \\ que se viere jamás en algún prado \\ algún pastor tan firme enamorado \\ como el infeliz Polio de Sincelo. \\ Aqueste de su Delia enamorado, \\ viendo su coraçón como diamante \\ por tener su esperança ya perdida, \\ en este gran pradal del sabio Anglante, \\ a la terrible muerte se ha entregado, \\ sin que fuesse de sí proprio homicida. (Martínez 2012, 14)
}

Ante esta historia pastoril, no faltan las referencias que, de un modo u otro, pudieron influir a Marcos Martínez, desde el conjunto de la literatura de pastores. Por un lado, como ya se ha mencionado, no se puede eludir la sombra que proyecta la materia clásica con esa ninfa Dafne a la que persigue Apolo, si bien la aventura acaba muy diferente a como se resuelve la huida de Delia, pues la ninfa, antes que caer en los brazos del dios griego, prefiere invocar a su padre para que la transforme en laurel. Aparte de ello, el retrato que se realiza del pastor Polio lo aleja de los principios del amor neoplatónico, que sí está presente en otros episodios de este tipo en obras como el Olivante de Laura o la Segunda parte de Espejo de príncipes y caballeros. En este caso, Polio desea el cuerpo de su amada. Aunque el autor destaca el amor que 
puede sentir hacia ella, este sentimiento no está idealizado ni sigue los ideales neoplatónicos; más bien se trata de una fuerza brutal que lo perturba y convierte, en palabras de Martín Romero (2009, 599-601), en un trastorno cercano a la enfermedad: amor hereos.

Por su parte, el tema del suicidio tampoco será algo nuevo en el conjunto del corpus caballeresco, pues ya contamos con antecedentes por ejemplo en la Segunda parte del Espejo del príncipes y caballeros. Pedro de Sierra introduce este tema en los personajes femeninos de Arcalanda y Herea como un medio para la defensa de su castidad y con un tratamiento cuidado que lo aleje de la condena religiosa (Sierra 2003).

\section{DE LA DESDEÑosa Delia A LA CRUEL MARCELA: HISTORIA DE DOS PASTORAS}

Centrándonos ya en el meollo de este trabajo, tras el análisis de la escena de Polio Sincelo y Delia, hay que destacar algunos aspectos llamativos que guardan cierto paralelismo con una historia posterior: la aventura de Grisóstomo y Marcela que Cervantes introduce entre los capítulos XII y XIIII de la Primera parte del Quijote. Durante la estancia de don Quijote y Sancho con unos cabreros, les llega la noticia de la muerte del joven estudiante reconvertido en pastor, Grisóstomo, a causa del amor no correspondido de Marcela. Tras conocer la historia de los jóvenes, el caballero, junto con su escudero, decide acompañar a los cabreros al entierro. El episodio se cierra con un amigo del joven pastor, Ambrosio, quien pretende grabar un epitafio sobre su sepultura, donde se cuenten las causas de la muerte de Grisóstomo.

Por su parte, Marcela es uno de los personajes femeninos que más ha llamado la atención de la crítica cervantina. En este sentido, destacan desde los trabajos clásicos sobre la retórica de su discurso de Hart y Rendall (1978) hasta el juego de los planos de realidad en la construcción discursiva de García (2004). Por supuesto, en relación con este trabajo cobran mayor importancia las ideas feministas plasmadas en las palabras de Marcela, y que plantearon una relectura del capítulo en esta línea ideológica (Jehenson 1990; Saffar 1993), incluso se ha llegado a considerar uno de los primeros discursos feministas en el plano literario (Falcón 1997). De forma paralela, no se puede ignorar otra vertiente que encuadra tanto a Marcela como su discurso dentro de las influencias del género hagiográfico en la literatura aurisecular (Gómez Moreno 2015).

Por su parte, el tema del suicidio puede extenderse a otras obras cervantinas, desde La Numancia al Persiles, pasando por otros capítulos del Quijote, como la historia de Cardenio y Luscinda (Sáez 2015). Sin embargo, dentro de la nómina cervantina destaca el tratamiento del tema en La Galatea, donde la muerte, y en especial el suicido, cobran un importante papel, como señaló Damiani (1984). Sobresale el personaje de Galercio, enamorado de la 
«cruel Gelasia», quien lo rechaza constantemente, lo que lo empuja no a uno, sino a dos intentos de suicidio. El primero sucede en el Libro IV ${ }^{5}$, con un puñal, y el segundo en el Libro VI, al intentar ahogarse en el río. Esta última escena aventura la futura aparición de Marcela en el Quijote, como señalaron López Estrada y López García-Berdoy (1999, 614):

\begin{abstract}
Alzaron los pastores los ojos y vieron encima de una pendiente roca que sobre el río caía una gallarda y dispuesta pastora, sentada sobre la mesma peña, mirando con risueño semblante todo lo que los pastores hacían, la cual fue luego de todos conocida por la cruel Gelasia (Libro VI, 614).
\end{abstract}

Volviendo al pasaje que nos ocupa, si bien hay diferencias evidentes entre los episodios de Marcos Martínez y el de Cervantes, como son la procesión de pastores que pretende enterrar a Grisóstomo o el hecho de que Marcela no esté casada (ni pretenda estarlo), al contrario de la situación de Delia, que además reta a sus enamorados a que defiendan sus sentimientos en la cueva del sabio Anglante, existen varios elementos que confluyen en ambos capítulos pastoriles. No en vano, resulta muy semejante la estructura del pastor que acaba suicidándose por un amor no correspondido, que en el Quijote se relata por los pastores amigos de Grisóstomo. Aparte, destaca el epitafio sobre la tumba, o el soneto en el caso de Marcos Martínez, además de la esquiva pastora que huye de los requiebros amorosos de sus amantes. De esta forma se aliñan varios ingredientes que adoban dos historias paralelas de clara raigambre pastoril.

En concreto, son reseñables ciertas cuestiones. En primer lugar, la consideración de Delia y Marcela como mujeres ingratas ante el rechazo que muestran hacia sus enamorados. En el caso de Delia, es Polio Sincelo quien la acusa de comportarse de forma poco adecuada ante un enamorado, así como de hacerle pasar por toda una serie de tormentos y de condenarlo a muerte por solicitarle entrar en la cueva del sabio Anglante. La acusación de Polio Sincelo se basa en la negativa de Delia a aceptar sus amores, y señala la ingratitud y el desprecio que realiza la pastora del amor que siente por ella, tras lo que se lamenta por su mala suerte y el estado de su afligido corazón. Así, deja claro con un discurso cargado de patetismo ante el personaje autorreferencial de Marcos Martínez que es la ingratitud de la pastora lo que lo conduce a querer abandonar este mundo. El tono lastimero que emplea el pastor busca amplificar su pena amorosa, culpando en parte a Marcos Martínez por haber evitado que se acercara a Delia, pero sobre todo a la propia pastora por su rechazo y por ser la causa directa de su muerte, como apunta en sus últimas palabras: «Ay Delia mía causadora de mi triste suerte».

5. «El pastor estaba ante ella de rodillas, con un cordel echado a la garganta y un cuchillo desenvainado en la derecha mano, y con la izquierda tenía asida a la pastora de un blanco cendal» (Libro IV, 457-458). 
En este sentido, el dibujo es muy semejante a la primera impresión que reciben don Quijote y Sancho de Marcela, a quien no conocen de primera mano hasta el final de este pequeño interludio pastoril en el capítulo XIIII, pero que ha sido presentada por los pastores que acompañan el cuerpo de Grisóstomo como una mujer cruel que, con sus desprecios, ha conducido al joven a la muerte. La primera referencia que hay de la pastora es en el capítulo XII cuando se notifica a los cabreros la muerte de Grisóstomo: «Murió esta mañana aquel famoso pastor estudiante llamado Grisóstomo, y se murmura que ha muerto de amores de aquella endiablada moza de Marcela» (XII, 128). Con estas palabras, el primer esbozo que tenemos de Marcela es completamente censurable, descrita como una mujer joven y soltera, 'endiablada', que la caracteriza como una figura negativa que causa un efecto letal sobre sus inocentes enamorados ${ }^{6}$.

Consecuentemente, el dibujo de Marcela se singulariza en esta línea según avanza la historia, especialmente cuando interviene Ambrosio, el amigo de Grisóstomo, quien no duda en tachar a Marcela de mujer cruel, vil y egoísta. Primero, en el capítulo XIII Ambrosio se refiere a los desdeños de la pastora antes de comenzar el entierro de Grisóstomo, al señalar el lugar donde se enterraría al joven, el último sitio donde sufrió el rechazo de la doncella, hecho que lo llevó a la muerte: «Y allí fue también donde la primera vez le declaró su pensamiento, tan honesto como enamorado, y allí fue la última vez donde Marcela le acabó de desengañar y desdeñar, de suerte que puso fin a la tragedia de su miserable vida» (XIII, 144). Más adelante, durante el entierro, Ambrosio continúa con sus críticas a la pastora por su comportamiento, detallando la pintura negativa de la mujer por su crueldad y arrogancia. En el polo opuesto se sitúa Grisóstomo, perfilado como un joven inocente y entregado al amor, cuya única falta es haberse enamorado de una mujer endiablada y desdeñosa cuyo egoísmo lo ha conducido a la muerte, según señala su círculo más cercano. Ambrosio sentencia en el capítulo XIIII: «Y con esto queda en su punto la verdad que la fama pregona de la bondad de Marcela, la cual, fuera de ser cruel, y un poco arrogante, y un mucho desdeñosa, la mesma envidia ni debe ni puede ponerle falta alguna» (XIIII, 152).

El rechazo hacia la joven llega a su cumbre cuando aparece en el entierro, descendiendo de las peñas firme y orgullosa, pero envuelta en una dignidad que más adelante sustentará con su discurso en defensa de su modo de vida y su elección vital. Ante la visión de la pastora, Ambrosio muestra su furia al compararla con un basilisco, con un Nerón o con Tulia, la hija del rey Tarquino, de forma que se pone de relevancia su naturaleza cruel, traicionera, venenosa y arrogante:

- ¿Vienes a ver, por ventura, ¡oh fiero basilisco destas montañas!, si con tu presencia vierten sangre las heridas deste miserable a quien tu crueldad

6. Aparte de los estudios citados, la bibliografía de Marcela resulta ingente. Otros trabajos conocidos son Marasso (1943, 44-60), Piluso (1967, 46-48), Rivers (1985), Hart (1989, 73-95) y O’Connor (2005). 
quitó la vida? ¿O vienes a ufanarte en las crueles hazañas de tu condición? $¿ \mathrm{O}$ a ver desde esa altura, como otro despiadado Nero, el incendio de su abrasada Roma? ¿O a pisar arrogante este desdichado cadáver, como la ingrata hija al de su padre Tarquino? (XIIII, 152).

En esta línea, son muy semejantes las críticas con las que Polio Sincelo acusa a Delia, ya analizadas previamente, con las que se la culpa de ser la causa de su muerte, además de comportarse de forma ingrata al rechazarlo por no estar dispuesto a entrar en la cueva del sabio Anglante, tal y como solicita a sus amadores. La huida de Delia y la intercesión del personaje ficcionalizado de Marcos Martínez, que detiene a Polio Sincelo, llevan al desenlace de la historia, donde el pastor declara que Delia ya no se verá más tiempo importunada por el amor del pastor, dibujándose a sí mismo Polio Sincelo como víctima frente a la actitud exigente de Delia: «... dile pues que le ha sido tan favorable su fortuna de averla de mis manos escapado, siendo tú d'ello causa, que viva de oy más contenta, pues no será más importunada del sin ventura Polio» (Martínez 2012, 13-14). Es necesario puntualizar que Martín Romero $(2009,600)$ identifica este episodio pastoril en el prólogo con la recreación de una historia sentimental que Martínez conocería, y que tendría un regusto de historia à clef, como se ha interpretado la Diana u otros libros de pastores autobiográficos.

En ambas historias, las dos pastoras destacan por su capacidad de decisión y su libertad. Aunque Delia está casada con el noble Tolomeo ${ }^{7}$, como señala Polio Sincelo y el propio Marcos Martínez ficcionalizado, disfruta también de una situación de libertad que le permite estar sola por el campo e interactuar con otros pastores, hasta el punto de reclamar a sus amadores que demuestren sus sentimientos mediante su paso por la cueva del sabio Anglante. Ella decide cómo deben actuar sus amantes, no duda en imponer sus condiciones y en rechazar las peticiones que no cumplen con sus indicaciones. La imagen de mujer casada de Delia se aleja de la realidad histórica que sí determinaría el porvenir y el futuro de Marcela en el Quijote, pues mientras Delia puede continuar paseando por el campo e interactuando con los pastores (y posibles amantes), la situación del personaje cervantino tras el matrimonio sería probablemente muy diferente.

Por su parte, la imagen que se plasma de Marcela es la de una mujer libre, que corre desenfadada por el bosque tras huir de las trabas de un matrimonio que la habría condenado al ámbito doméstico y a la autoridad de su marido. Fosalba apunta, en relación con el discurso de Marcela, que la pastora se convierte en su propia «letrada defensora» con un gran discurso judicial que justificaría su retórica feminista gracias a la dialéctica retórica y argumentativa siglodorista $(2004,54)$. El deseo de vivir al margen de la sociedad, sin

7. «Y aviendo su plática entendido, viendo la poca razón del sin ventura amante, queriendo adulterar el noble Tolomeo esposo de la agraciada Delia [...]

- ¿Qué te ha movido, desleal amante, en querer con tan abominable modo injuriar la bella pastora, siendo con otro casada?» (Martínez 2012, 13). 
someterse a los designios patriarcales, lleva a Marcela a huir al bosque y pasar sus días aislada, sin querer mantener un contacto con las demás personas, a las que rehúye. Este deseo de libertad, independencia y el no querer someterse a nadie conduce a Marcela a rechazar a Grisóstomo. Sin embargo, don Quijote parece el único que comprende y defiende la decisión de la pastora, pues niega su responsabilidad en la muerte del joven ${ }^{8}$. El resto de los personajes, desde los cabreros a los amigos de Grisóstomo, arremeten contra Marcela, a quien tachan de cruel por su actitud de rechazo, e incluso esperan pronto que alguien sea capaz de domar semejante fiera, tal y como describen a la pastora a don Quijote en los primeros compases de la aventura en el capítulo XII:

Libre y desenfadadamente triunfa la hermosa Marcela, y todos los que la conocemos estamos esperando en qué ha de parar su altivez y quién ha de ser el dichoso que ha de venir a domeñar condición tan terrible y gozar de hermosura tan estremada (XII, 134).

En este sentido, Marcela es vista por los personajes masculinos (salvo don Quijote) como un animal salvaje al que es necesario domar por medio de un matrimonio que la devuelva al ámbito doméstico, el espacio reservado a la mujer donde desarrollar sus labores y su vida familiar. Los personajes masculinos, desde los cabreros hasta los amigos de Grisóstomo, cuestionan su libertad, pues no creen que tenga derecho a vivir libre en el bosque y a rechazar las propuestas matrimoniales de Grisóstomo. En relación con la alocución hecha por Marcela, Lorenzo Arribas señala que «termina de una manera incomprensible en un contexto patriarcal» (2008, s.p.), pues no reconoce como interlocutores a quienes la valoran por sus riquezas o como una posible buena esposa. Esta idea coincide con la resistencia a la pérdida de la individualidad inserta en un discurso de tipo subversivo para Wright (2010).

En relación de nuevo con el discurso de Marcela, la joven rechaza no solo el amor como una obligación a través del estado del matrimonio, sino también el propio sistema social que dejaba sin apenas opciones a las mujeres. Incluso, cuestiona y reduce al absurdo ciertas ideas del amor neoplatónico, lo que da al personaje ciertos visos realistas que lo alejan del modelo pastoril (Díez Fernández 2004, 132-133). De esta forma, mientras que el resto de los pastores esperan que Marcela vuelva a la esfera social que le corresponde como mujer, el espacio cerrado y doméstico en tanto que se convierta en esposa y madre, ella se opone a esta situación. La libertad es, para Marcela, la elección

8. «-Ninguna persona, de cualquier estado y condición que sea, se atreva a seguir a la hermosa Marcela, so pena de caer en la furiosa indignación mía. Ella ha mostrado con claras y suficientes razones la poca o ninguna culpa que ha tenido en la muerte de Grisóstomo y cuán ajena vive de condescender con los deseos de ninguno de sus amantes; a cuya causa es justo que, en lugar de ser seguida y perseguida, sea honrada y estimada de todos los buenos del mundo, pues muestra que en él ella es sola la que con tan honesta intención vive» (XIIII, 156). 
voluntaria y consciente de una vida en soledad, a la que puede acceder también gracias al dinero y los bienes que conserva. Su fortuna personal junto con su condición familiar especial, según señala Díez Fernández, llevan a que su discurso resulte convincente dentro de la posibilidad de elección de Marcela: «Las rotundas, argumentadas y sólidas declaraciones de Marcela suponen una defensa del derecho a elegir una vida, lo que, al tratarse de una mujer, se carga de un intenso sentido reivindicativo» $(2004,139)$.

Ante la sucesión de acontecimientos y la muerte del joven, los amigos de Grisóstomo no parecen dispuestos a dejar escapar a Marcela, a pesar de su discurso en defensa de la libertad de elección y su deseo de vivir aislada. Solo la intervención de don Quijote evita que persigan a la pastora. Sin embargo, el enfado de los hombres que no han conseguido castigar y 'domeñar' a Marcela, por su decisión de vivir libre y devolverla a su posición original en la sociedad, sigue patente a pesar de las palabras del viejo hidalgo. La idea queda anclada en el epitafio que piensa colocar Ambrosio en la sepultura como señala en el capítulo XIIII:

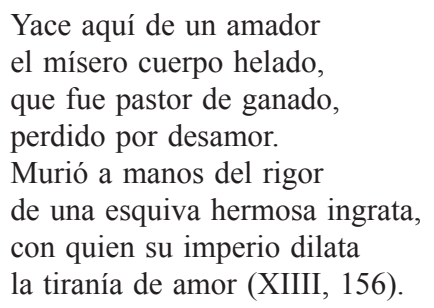

Con esta despedida, está claro que Ambrosio sigue posicionándose a favor de su amigo Grisóstomo, si bien el público, al igual que don Quijote, ha tenido la ocasión de escuchar la justificación y el punto de vista de Marcela sobre todo lo que ha acontecido. El hidalgo manchego defiende la actitud de la pastora, pero el resto de los personajes masculinos no parecen aceptarlo, especialmente Ambrosio quien en su epitafio sigue tildando de 'ingrata' a Marcela, además de dibujarla como una mujer caprichosa que llevó a la muerte a Grisóstomo con su rechazo. En el epitafio, Ambrosio no tiene intención de descargar a Marcela de culpa en la muerte de su amigo, al subrayar los dos aspectos que los personajes masculinos han empleado para describir a Marcela: su belleza y su desdén, que lleva a enamorar a los hombres. Las consecuencias de esta situación resultan terribles, en especial para Grisóstomo, a quien ha conducido a la tumba. De esta forma, en el epitafio se le sigue considerando un «amador» y una víctima del desamor y de la egoísta Marcela, a quien se culpabiliza.

Por otro lado, el soneto que el personaje de Marcos Martínez talla sobre la tumba de Polio Sincelo, no clama abiertamente la crueldad de la pastora, salvo por el verso décimo que declara «viendo su coraçón como diamante», en referencia a la dureza del corazón de Delia con sus amantes. Sin embargo, junto con la descripción de la infelicidad de Polio Sincelo en el octavo verso, 
«como el infeliz Polio Sincelo», el soneto se centra en describir la trágica historia de amor. La diferencia esencial entre ambos consiste en que, mientras Marcos Martínez se focaliza en el pastor Polio y en el ambiente creado por su desamor, así como en la descripción de su trágica historia pues no quiere que tal cuestión caiga en el olvido, Ambrosio irá un paso más allá. En consecuencia, el amigo de Grisóstomo pone el foco sobre Marcela, especialmente en la segunda parte del epitafio, de modo que su actitud hacia el joven, así como su decisión de no corresponderle y de querer vivir una vida independiente en libertad, como ella misma ha defendido, se convierten para Ambrosio en ingratitud. De esta manera, Marcela copa gran parte del protagonismo en el epitafio, descrita como el personaje negativo que ha causado la muerte de Grisóstomo; lo ha atraído cual sirena con su belleza, pero lo ha desdeñado y ha rechazado su amor. A pesar de sus justificaciones en su gran discurso y de la defensa que hace de ella don Quijote, Ambrosio junto con otros pastores no se lo perdonan, y la efigie de Marcela en el epitafio se tallará con el apelativo de «hermosa ingrata».

Ante lo visto, si bien los episodios de Delia y Polio Sincelo, y de Marcela y Grisóstomo cuentan con elementos que los diferencian indudablemente, existe una serie de paralelismos comunes. En primer lugar, la estructura superficial de las historias resulta similar, con el pastor rechazado por su amada que concluye con su muerte, a causa de este rechazo amoroso. En consecuencia, ello provoca la acusación, en un caso de Polio Sincelo y en otro de Ambrosio, de ingratitud y desdén por parte de las mujeres al no haber querido aceptar a sus enamorados. Ante las muertes de Polio Sincelo y Grisóstomo a causa del desamor, el primero no duda en acusar a Delia, mientras que los amigos de Grisóstomo, en especial Ambrosio, muestran su resentimiento contra Marcela al aparecer en el entierro del joven. El caso de la pastora Marcela resulta llamativo por el trasfondo, pues la censura del resto de personajes tiene como núcleo su modo de vida independiente, aislada socialmente en el bosque por propia voluntad al no querer perder su libertad individual al casarse. Esta situación molesta especialmente a los personajes masculinos, quienes no paran de preguntarse quién conseguirá domar a la pastora, como si de un animal salvaje se tratara, con la implicación de devolverla a la esfera social que correspondería a una mujer de su época: el ámbito doméstico. Finalmente, el paralelismo entre ambos episodios se cierra con el epitafio final que se sitúa sobre la tumba de los fallecidos. El personaje ficcional de Marcos Martínez escribe el soneto con ánimo de que su historia no caiga en el olvido, pero en él no habrá un ataque directo contra Delia, al igual que su actitud hacia la pastora a lo largo del capítulo no ha sido censurable. Ello contrasta con el dibujo que se plasma de Marcela en el epitafio de Ambrosio, quien arremete contra la joven por su actitud desdeñosa con Grisóstomo, a pesar de que previamente ha justificado sus acciones e, incluso, ha encontrado en don Quijote un defensor de su modo de vida.

Con todo ello, esta pequeña nota ha pretendido ahondar un poco más en la relación del libro de caballerías con la literatura pastoril, así como en las co- 
nexiones que se establecen con la obra de Cervantes, que tiene la ficción caballeresca como uno de sus pilares esenciales. Como ya indiqué al comienzo de este trabajo, se han pretendido señalar las similitudes entre este episodio pastoril-caballeresco inserto en un libro de caballerías tardío y la trama de Marcela sin que ello quiera decir que exista dependencia entre ellos. Su interés reside en poner en evidencia la sintonía de intereses por parte de Cervantes y Marcos Martínez, así como analizar la actitud que se toma hacia la mujer.

En este sentido, la mujer huidiza que rechaza el requerimiento de su enamorado se pinta como una mujer cruel y desdeñosa, que con sus acciones lleva a la tumba al pastor enamorado, desenlace del que se la considera responsable. Si bien no creo que sea correcto interpretar el texto o las actitudes de los personajes fuera de su contexto histórico-social y vital, es interesante resaltar en ambas escenas la reacción de los personajes masculinos ante el rechazo de Delia y Marcela a sus respectivos enamorados. Ello dará una muestra de la mentalidad social de los Siglos de Oro de lo que se espera de las féminas, del ámbito en el que deben permanecer, la esfera doméstica, y del comportamiento que deben asumir ante el hombre que les declara su amor, si no quieren pasar a la historia como mujeres desdeñosas y crueles.

\section{BIBLIOGRAFÍA CITADA}

Alvar, Carlos y José Manuel Lucía Megías. 2001. «Los libros de caballerías en la época de Felipe II». En Silva. Studia philologica in honorem Isaias Lerner, ed. Isabel Lozano Renieblas y Juan Carlos Mercado, 25-35. Castalia: Madrid.

Avalle-Arce, Juan Bautista. 1975. La novela pastoril española. Madrid: Istmo.

Cacho Blecua, Juan Manuel, coord. 2007. De la literatura caballeresca al «Quijote», eds. Ana Carmen Bueno Serrano, Patricia Esteban Erlés y Karla Xiomara Luna Mariscal. Zaragoza: Prensas Universitarias de Zaragoza.

Campos García-Rojas, Axayácatl. 2006. «Espejo de príncipes y caballeros» (Parte III) de Marcos Martínez (Alcalá de Henares, Juan Íñiguez de Lequerica, 1587). Guía de lectura. Alcalá de Henares: Centro de Estudios Cervantinos.

Campos García-Rojas, Axayácatl. 2010. «Estructura onírica y configuración del "prólogo literario" en Espejo de príncipes y caballeros (parte III): la aventura de Marcos Martínez». En Actas del XIII congreso de la Asociación Hispánica de Literatura Medieval (Valladolid, 15 a 19 de septiembre de 2009). In memoriam Alan Deyermond, coords. José Manuel Fradejas Rueda, Déborah Dietrick Smithbauer, María Jesús Díez Garretas y Demetrio Martín Sanz, 503-518. Valladolid: Ayuntamiento de Valladolid, Universidad de Valladolid, Asociación Hispánica de Literatura Medieval.

Campos García-Rojas, Axayácatl. 2012. «El ciclo de Espejo de príncipes y caballeros [1555-1580-1587]». Edad de Oro 21: 389-430.

Campos García-Rojas, Axayácatl. 2015. «Letras y motes con función narrativa en el Espejo de príncipes y caballeros (parte III)». Revista de Cancioneros Impresos y Manuscritos 4: 13-46.

Campos García-Rojas, Axayácatl y Gabriela Martin López. 2018. «Las categorías genológicas en los textos breves insertos en libros de caballerías hispánicos del siglo XVI». Lingüistica y Literatura 74: 56-77. 
Cervantes, Miguel de. 1999. Don Quijote de la Mancha, ed. Francisco Rico. Barcelona: Instituto Cervantes, Crítica.

Cervantes, Miguel de. 1999. La Galatea, eds. Francisco López Estrada y María Teresa López García-Berdoy. Madrid: Cátedra.

Cravens, Sidney P. 1976. Feliciano de Silva y los antecedentes de la novela pastoril en sus libros de caballerías. Chapel Hill: Estudios de Hispanófila.

Damiani, Bruno. 1984. «Death in Cervantes' Galatea». Cervantes 4(1): 53-78.

Díez Fernández, José Ignacio. 2004. Tres discursos de mujeres: poética y hermenéutica cervantinas. Alcalá de Henares: Centro de Estudios Cervantinos.

Eisenberg, Daniel y M. ${ }^{a}$ Carmen Marín Pina. 2000. Bibliografía de los libros de caballerías castellanos. Zaragoza: Universidad.

Falcón, Lidia. 1997. Amor, sexo y aventuras en las mujeres del Quijote. Madrid: Vindicación Feminista.

Ferrer Valls, Teresa. 1999. «Bucolismo y teatralidad cortesana bajo el reinado de Felipe II». Voz y Letra 10: 3-18.

Fosalba, Eugenia. 2004. «El episodio de Marcela y Grisóstomo en el contexto del Quijote». Philologia Hispalensis 18(2): 49-62.

García, Martha. 2004. «Marcela ¿defendida o defensora?: un tribunal cervantino». Anuario de estudios cervantinos 1: 165-174.

Gómez Moreno, Ángel. 2015. «Marcela y don Quijote: apuntes de hagiografía y cristología». Anales Cervantinos 47: 355-370. https://doi.org/10.3989/anacervantinos.2015

Hart, Thomas R. 1989. Cervantes and Ariosto. Renewing Fiction. Princeton: University.

Hart, Thomas R. y Steven Rendall. 1978. «Rhetoric and Persuasion in Marcela's Address to the Sheperds». Hispanic Review XLVI: 287-298.

Jehenson, Myriam Yvonne. 1990. «The Pastoral Episode in Cervantes' Don Quijote: Marcela once again». Cervantes 10(2): 15-35.

López Estrada, Francisco. 1974. Los libros de pastores en la literatura española, vol. 1. Madrid: Gredos.

Lorenzo Arribas, José Miguel. 2008. «El discurso feminista de la pastora Marcela». En Rinconete. Madrid: Centro Virtual Cervantes. Accesible en: $<$ https://cvc.cervantes.es/ el_rinconete/anteriores/abril_08/02042008_01.htm>.

Lucía Megías, José Manuel y Emilio José Sales Dasí. 2008. Libros de caballerías castellanos (siglos XVI-XVII). Madrid: Laberinto.

Marasso, Arturo. 1943. La invención del «Quijote». Buenos Aires: Biblioteca Nueva.

Marín Pina, M. ${ }^{a}$ Carmen. 2011. Páginas de sueños. Estudios sobre los libros de caballerías castellanos. Zaragoza: Institución Fernando el Católico.

Martín Romero, José Julio. 2007. Entre el Renacimiento y el Barroco. Pedro de la Sierra y su obra. Zaragoza: Prensas Universidad de Zaragoza.

Martín Romero, José Julio. 2009. «La temática pastoril en los libros de caballerías de época de Felipe II». Nueva Revista de Filología Hispánica LVII, 2: 563-605.

Martínez, Marcos. 2012. Espejo de príncipes y caballeros (Tercera parte), ed. Axayácatl Campos García-Rojas. Alcalá de Henares: Centro de Estudios Cervantinos.

Mérida Jiménez, Rafael M. 2013. Transmisión y difusión de la literatura caballeresca. Doce estudios de recepción cultural hispánica (siglos XIII-XVII). Lérida: Universitat de Lleida.

Muguruza, Isabel. 1995. «El pastor en los libros de caballerías: el caso del Olivante de Laura, de Antonio de Torquemada». Cuadernos para investigación de la literatura hispánica 20: 197-215.

O'Connor, Thomas Austin. 2005. «Marcela, seguidora de Ártemis: el fundamento social, cultural y mítico del episodio de Marcela y Grisóstomo». En Cervantes y su mundo, 
coords. Kurt Reichenberger y Darío Fernández-Morera, 369-390. Kassel: Reichenberger, 2 vols.

Piluso, Robert V. 1967. Amor, matrimonio y honra en Cervantes. Nueva York: Las Américas Publishing Company.

Prieto, Antonio. 1986. La prosa española del siglo XVI. Madrid: Cátedra.

Riley, Edward C. 1982. "A premonition of pastoral in Amadis de Gaula». Bulletin of Hispanic Studies 59(3): 226-229.

Río Nogueras, Alberto del. 2001. «El harpa y la churumbela. Notas sobre el entretenimiento cortesano en los libros de caballerías de Feliciano de Silva». En Actas del V Congreso Internacional de la Asociación Internacional Siglo de Oro (AISO), Münster 20-24 de julio de 1999, coord. Christoph Strosetzki, 1087-1097. Madrid - Frankfurt: Iberoamericana - Vervuert.

Río Nogueras, Alberto del. 2002. «Las Bucólicas de Feliciano de Silva en sus libros de caballerías». En La Égloga. VI Encuentro Internacional sobre Poesía del Siglo de Oro (Universidades de Sevilla y Córdoba, 20-23 de noviembre de 2000), ed. Begoña López Bueno, 91-119. Sevilla: Universidad - Grupo P.A.S.O.

Rivers, Elias L. 1985. «Pastoral, Feminism and Dialogue in Cervantes». En «La Galatea» de Cervantes cuatrocientos años después (Cervantes y lo pastoril), ed. Juan Bautista Avalle-Arce, 7-15. Newark: Juan de la Cuesta.

Sáez, Adrián J. 2015. «Un 'pecado tan malo y feo': variaciones cervantinas sobre el suicidio». Iberoromania 82: 202-217.

Saffar, Ruth. 1993. «In Marcela's Case». En Quixotic Desire: Psychoanalytic Perspectives on Cervantes, eds. Ruth Saffar y Diana de Armas Wilson, 157-178. Ithaca, Nueva York: Cornell University Press.

Sierra, Pedro. 2003. Espejo de príncipes y caballeros (Segunda parte), ed. José Julio Martín Romero. Alcalá de Henares: Centro de Estudios Cervantinos.

Wright, Amy E. 2010. «Mothering a feminine dialectic. Cervantes "murderous sheperdess" Marcela as Medusa». En Don Quijote y la narrativa posmoderna, coord. Mercedes Juliá, 48-64. Cádiz: Universidad de Cádiz. 